\title{
Novel Similarity Measures, Entropy of Intuitionistic Fuzzy Sets and their Application in Software Quality Evaluation
}

Xuan Thao Nguyen ( $\nabla$ nguyenxuanthao@duytan.edu.vn )

Institute of Research and Development, Duytan University, Danang 550000, Vietnam

Shuo Yan Chou

Department of Industrial Management, National Taiwan University of Science and Technology

\section{Research Article}

Keywords: Intuitionistic fuzzy set, similarity measure, software quality model

Posted Date: June 3rd, 2021

DOI: https://doi.org/10.21203/rs.3.rs-563745/v1

License: (c) (i) This work is licensed under a Creative Commons Attribution 4.0 International License.

Read Full License 


\title{
NOVEL SIMIILARITY MEASURES, ENTROPY OF INTUITIONISTIC FUZZY SETS AND THEIR APPLICATION IN SOFTWARE QUALITY EVALUATION
}

\author{
Nguyen Xuan Thao ${ }^{1 *}$, Shuo-Yan Chou ${ }^{2}$ \\ ${ }^{1}$ Faculty of Information Technology, Vietnam National University of Agriculture, \\ Trau Quy, Gia Lam, Ha Noi, Viet Nam. \\ Email:nxthao@vnua.edu.vn \\ ${ }^{2}$ Department of Industrial Management, National Taiwan University of Science \\ and Technology, 43, Sect. 4, Keelung Road, Taipei 10607, Taiwan. \\ Email:sychou@mail.ntust.edu.tw
}

\begin{abstract}
Intuitionistic fuzzy sets (IFSs), including member and nonmember functions, have many applications in managing uncertain information. The similarity measures of IFSs proposed to represent the similarity between different types of sensitive fuzzy information. However, some existing similarity measures do not meet the axioms of similarity. Moreover, in some cases, they could not be applied appropriately. In this study, we proposed some novel similarity measures of IFSs constructed by combining the exponential function of membership functions and the negative function of non-membership functions. In this paper, we also proposed a new entropy measure as a stepping stone to calculate the weights of the criteria in the proposed multi-criteria decision making (MCDM) model. The similarity measures used to rank alternatives in the model. Finally, we used this MCDM model to evaluate the quality of software projects.
\end{abstract}

Keywords: Intuitionistic fuzzy set, similarity measure, software quality model.

\section{Introduction}

In 1986, Atanassov introduced intuitionistic fuzzy sets (IFSs) (Atanassov, 1986), which are a generalization of a fuzzy set (Zadeh, 1965). An IFS considers the information involving membership functions and non-membership functions. From their inception to the present day, IFSs have been proven to be a highly effective tool for processing uncertainties in real-world problems, including pattern recognition and decision-making. Later, Atanassov and Gargov introduced interval-valued IFSs (IVIFSs), in which membership functions and non-membership 
functions are subintervals of a unit interval [0, 1] (Atanassov and Gargov, 1989). Similar to fuzzy sets, IFSs have wide applications in processing uncertain data for various purposes, such as decision-making, medical diagnoses, and agriculture (Szmidt and Kacprzyk, 1996; Xu, 2010; Papakostas et al., 2013; Shidpour et al., 2013; Bharati and Singh, 2014; Li and Zeng, 2015; Liu et al., 2016; Xuan Thao, 2018; Thao and Duong, 2019; Thao et al., 2019; Joshi, 2020; Garg and Kumar, 2020; Xue \& Deng, 2020; Thao ${ }^{\mathrm{a}}$, 2021). Along with distance and correlation measures, similarity measures of IFSs have been studied and widely used in many fields, such as decision-making, machine learning, and pattern recognition ( $\mathrm{Li}$ and Cheng, 2002; Szmidt Kacprzyk, 2004; Xu, 2007; Ye, 2011; Hwang et al., 2012; Park et al., 2013; Rajarajeswari and Uma, 2013 Shi and Ye, 2013; Tian, 2013; Song et al., 2015; J. Ye, 2016). Today, they still are a hot topic attracting research attention. Liang and Shi proposed a similarity measure of IFSs and applied the measure for pattern recognition (Liang and Shi, 2003). Xu and Chen developed a similarity measure by using the distance measure in the multi-attribute decision-making process (Xu, 2007; Xu and Chen, 2008). Furthermore, Zhou proposed a similarity measure and applied it in multi-criteria decision-making (MCDM) process (Zhou, 2016). The aforementioned methods used either polynomial or fractional functions. In 2013, similarity measures of IFSs based on the cotangent function investigated and applied to medical diagnoses (Rajarajeswari and Uma, 2013; Tian, 2013). Ye introduced vector cosine similarity measures for IFSs and presented their applications (Ye, 2011). In 2016, Ye introduced similarity measures of IFSs based on the cosine function for decision-making in mechanical design schemes (Ye, 2016). These similarity measures of Ye alleviated the limitations of other existing measures. These limitations are discussed in section 3 (examples 1 and 2). These suggest that we continue to search for new measures to overcome the limitations of existing measures.

The International Organization for Standardization (ISO, 2017) declared that "The scope of the application of the quality models including supporting the specification and evaluation of software and software-intensive computer systems based on different perspectives by using the specifications associated with their acquisition, requirements, development, use, evaluation, support, maintenance, 
quality assurance and control, and audit. For example, the models can be used by developers, acquirers, quality assurance and control staff, and independent evaluators, particularly those responsible for specifying and evaluating software product quality". Activities during product development that can benefit from the use of these quality models are as follows:

- Identifying software and system requirements

- Validating the comprehensiveness of requirement definitions

- Identifying software and system design objectives

- Identifying software and system testing objectives

- Identifying quality control criteria as part of quality assurance

- Identifying acceptance criteria for a software product and/or a software-intensive computer system

- Establishing measures of quality characteristics in support of these activities.

The quantification of these criteria to evaluate and rank software has practical significance. This will depend on human feelings and knowledge. Whereas IFS has proven to be an effective tool when dealing with this kind of knowledge. In this paper, we applied new measures on IFSs to the problem of pattern recognition and decision-making software quality assessment.

Contribution of this study as follows:

+ we introduced a new similarity measure of IFSs by combining exponential and negative functions.

+ Compare new proposed similarity measure to see that they are feasible.

+ To propose new entropy of IFS by combining exponential and negative functions.

+ Compare new proposed entropy measure to see that they are reasonable. 
+ Recommend a method to rank and evaluate product quality. It is useful to help us consider to select, evaluate software quality. This is done through illustrative numerical examples.

+ Compare the new method to some other ranking method to demonstrate the performance of the new method.

The remainder of this paper is organized as follows: Section 2 reviews the concepts of IFSs and IVIFSs and their similarity measures. Section 3 describes how we constructed a new similarity measure between different IFSs and provides some examples in which the results obtained using our method are compared with those obtained using other methods. Section 4 presents the intuitionistic fuzzy software quality model and provides an example to illustrate the model. Moreover, the results of the model obtained using our similarity measure were compared with the results of a model obtained using the similarity measure proposed by (Ye, 2011; Ye, 2016). Finally, in section 5, we provide a conclusion about our method and present the future research.

\section{Preliminary}

Let $X$ be a universal set. We reminder some concept related to IFS as follows. Definition 1 (Atanassov, 1986) An intuitionistic fuzzy set on $X$ is defined by form

$$
A=\left\{\left(x, \mu_{A}(x), v_{A}(x)\right) \mid x \in X\right\}
$$

in which $\mu_{A}(x) \in[0,1]$ and $v_{A}(x) \in[0,1]$ are the membership and non-membership degree of the element $x$ in $X$ to $A$, respectively, such that

$$
\mu_{A}(x)+v_{A}(x) \leq 1, \forall x \in X .
$$

The degree of hesitant of element $x \in X$ in $A$ is $\pi_{A}(x)=1-\left(\mu_{A}(x)+v_{A}(x)\right)$.

We denote $\operatorname{IFS}(X)$ is the collection of all IFSs on $X$.

For two intuitionistic fuzzy sets $A, B \in \operatorname{IFS}(X)$, we have:

- Subset: $A \subset B$ if only if $\mu_{A}(x)<\mu_{B}(x)$ and $v_{A}(x)>v_{B}(x)$ for all $x \in X$. 
- Equal: $A=B$ if only if $\mu_{A}(x)=\mu_{B}(x)$ and $v_{A}(x)=v_{B}(x)$ for all $x \in X$.

- For all $\lambda>0$, we have

$$
A^{\lambda}=\left\{\left(x, \mu_{A}^{\lambda}(x), 1-\left(1-v_{A}(x)\right)^{\lambda}\right) \mid x \in X\right\}
$$

Now, we recall the similarity measure in literal.

Given a finite universal set $X=\left\{x_{1}, x_{2}, \ldots, x_{n}\right\}$. Let $A=\left\{\left(x_{i}, \mu_{A}\left(x_{i}\right), v_{A}\left(x_{i}\right)\right) \mid x_{i} \in X\right\}$, $B=\left\{\left(x_{i}, \mu_{B}\left(x_{i}\right), v_{B}\left(x_{i}\right)\right) \mid x_{i} \in X\right\}$ be two IFSs on $X$.

Definition 2. (Li and Cheng, 2002) A mapping S: $\operatorname{IFS}(X) \times \operatorname{IFS}(X) \rightarrow[0,1]$ is the similarity measure of the intuitionistic fuzzy sets if it satisfies the following conditions:

(S1) $0 \leq \mathrm{S}(\mathrm{A}, \mathrm{B}) \leq 1$ for all $\mathrm{A}, \mathrm{B} \in \operatorname{IFS}(X)$,

(S2) $\mathrm{S}(\mathrm{A}, \mathrm{B})=\mathrm{S}(\mathrm{B}, \mathrm{A})$ for all $\mathrm{A}, \mathrm{B} \in \operatorname{IFS}(X)$,

(S3) $\mathrm{S}(\mathrm{A}, \mathrm{A})=1$ for all $\mathrm{A} \in \operatorname{IFS}(X)$,

(S4) For all $\mathrm{A}, \mathrm{B}, \mathrm{C} \in \operatorname{IFS}(X)$. If $A \subseteq B \subseteq C$ then $S(A, C) \leq \min \{S(A, B), S(B, C)\}$.

\section{The new similarity measures of the IFSs}

Let $X=\left\{x_{1}, x_{2}, \ldots, x_{n}\right\}$ be a finite universal set, $A$ and $B$ are two arbitrary IFSs on $X$. We denote $S_{i}^{\mu}(A, B)=\frac{e^{-\mid \mu_{A}\left(x_{i}\right)-\mu_{B}\left(x_{i}\right)}-e^{-1}}{1-e^{-1}}, \quad S_{i}^{\nu}(A, B)=1-\left|v_{A}\left(x_{i}\right)-v_{B}\left(x_{i}\right)\right|$ for all $i=1,2, \ldots, n$.

Proposition 1. Let $A$ and $B$ be two arbitrary IFSs in $X$. Then $S_{i}^{\mu}(A, B)$ and $S_{i}^{v}(A, B) \quad(i=1,2, \ldots, n)$ satisfy the following conditions:

(s1) $0 \leq S_{i}^{\mu}(A, B), S_{i}^{v}(A, B) \leq 1$ for all $\mathrm{A}, \mathrm{B} \in \operatorname{IFS}(X)$.

(s2) $S_{i}^{\mu}(A, B)=S_{i}^{\mu}(B, A)$ and $S_{i}^{v}(A, B)=S_{i}^{v}(B, A)$ for all $\mathrm{A}, \mathrm{B} \in \operatorname{IFS}(X)$

(s3) $S_{i}^{\mu}(A, A)=S_{i}^{v}(A, A)=1$ for all $\mathrm{A} \in \operatorname{IFS}(X)$.

(s4) For all $\mathrm{A}, \mathrm{B}$ and $\mathrm{C} \in \operatorname{IFS}(X)$. If $A \subseteq B \subseteq C$ then

$S_{i}^{\mu}(A, C) \leq \min \left\{S_{i}^{\mu}(A, B), S_{i}^{\mu}(B, C)\right\}$ 
and

$$
S_{i}^{\nu}(A, C) \leq \min \left\{S_{i}^{\nu}(A, B), S_{i}^{\nu}(B, C)\right\} .
$$

\section{Proof.}

(s1). For all $A \in \operatorname{IFS}(X)$ and $B \in \operatorname{IFS}(X)$, we have $-1 \leq-\left|\mu_{A}\left(x_{i}\right)-\mu_{B}\left(x_{i}\right)\right| \leq 0$

and

$$
0 \leq\left|v_{A}\left(x_{i}\right)-v_{B}\left(x_{i}\right)\right| \leq 1
$$

so that

$$
e^{-1} \leq S_{i}^{\mu}(A, B)=e^{-\left|\mu_{A}\left(x_{i}\right)-\mu_{B}\left(x_{i}\right)\right|} \leq 1
$$

and

$$
0 \leq S_{i}^{v}(A, B)=1-\left|v_{A}\left(x_{i}\right)-v_{B}\left(x_{i}\right)\right| \leq 1 .
$$

(s2). It is obvious.

(s3). Consider two intuitionistic fuzzy sets $\mathrm{A}$ and $\mathrm{B}$ on $X$. If $A=B$ then $\mu_{A}\left(x_{i}\right)=\mu_{B}\left(x_{i}\right), v_{A}\left(x_{i}\right)=v_{B}\left(x_{i}\right)$. This implies that $S_{i}^{\mu}(A, B)=1, S_{i}^{v}(A, B)=1$.

(s4). For three intuitionistic fuzzy sets $\mathrm{A}, \mathrm{B}$ and $\mathrm{C}$ such that $\mathrm{A} \subseteq \mathrm{B} \subseteq \mathrm{C}$, then we have $\mu_{A}\left(x_{i}\right) \leq \mu_{B}\left(x_{i}\right) \leq \mu_{C}\left(x_{i}\right)$, and $v_{C}\left(x_{i}\right) \leq v_{B}\left(x_{i}\right) \leq v_{A}\left(x_{i}\right)$. So that, we have

$$
\max \left\{\left|\mu_{A}\left(x_{i}\right)-\mu_{B}\left(x_{i}\right)\right|,\left|\mu_{B}\left(x_{i}\right)-\mu_{C}\left(x_{i}\right)\right|\right\} \leq\left|\mu_{A}\left(x_{i}\right)-\mu_{C}\left(x_{i}\right)\right|
$$

and

$$
\max \left\{\left|v_{A}\left(x_{i}\right)-v_{B}\left(x_{i}\right)\right|,\left|v_{B}\left(x_{i}\right)-v_{C}\left(x_{i}\right)\right|\right\} \leq\left|v_{A}\left(x_{i}\right)-v_{C}\left(x_{i}\right)\right| .
$$

Then we have

$$
\min \left\{-\left|\mu_{A}\left(x_{i}\right)-\mu_{B}\left(x_{i}\right)\right|,-\left|\mu_{B}\left(x_{i}\right)-\mu_{C}\left(x_{i}\right)\right|\right\} \geq-\left|\mu_{A}\left(x_{i}\right)-\mu_{C}\left(x_{i}\right)\right|,
$$

and

$$
\min \left\{-\left|v_{A}\left(x_{i}\right)-v_{B}\left(x_{i}\right)\right|,-\left|v_{B}\left(x_{i}\right)-v_{C}\left(x_{i}\right)\right|\right\} \geq-\left|v_{A}\left(x_{i}\right)-v_{C}\left(x_{i}\right)\right| .
$$

Since, we obtain 


$$
S_{i}^{\mu}(A, C) \leq \min \left\{S_{i}^{\mu}(A, B), S_{i}^{\mu}(B, C)\right\}
$$

and

$$
S_{i}^{\nu}(A, C) \leq \min \left\{S_{i}^{\nu}(A, B), S_{i}^{\nu}(B, C)\right\}
$$

Now, we can define the similarity measures of the intuitionistic fuzzy sets that assigned with the weight of each element in the universal set.

We assume that each element $x_{i} \in X$ assigned with a weight $\omega_{i} \in[0,1](i=1,2, \ldots, n$ ) such that $\sum_{i=1}^{n} \omega_{i}=1$.

Definition 3. A mapping S: $\operatorname{IFS}(X) \times \operatorname{IFS}(X) \rightarrow[0,1]$ is defined by

$$
\mathrm{S}_{1}(A, B)=\sum_{i=1}^{n} \omega_{i} \frac{S_{i}^{\mu}(A, B)+S_{i}^{\nu}(A, B)}{2}
$$

Theorem 1. Let $A$ and $B$ be two arbitrary IFSs in $X$. The expression $\mathrm{S}_{1}(A, B)$ in the eq. (2) satisfies the following conditions:

(S1) $0 \leq \mathrm{S}_{1}(A, B) \leq 1$ for all $\mathrm{A}, \mathrm{B} \in \operatorname{IFS}(X)$.

(S2) $\mathrm{S}_{1}(\mathrm{~A}, \mathrm{~B})=\mathrm{S}_{1}(\mathrm{~B}, \mathrm{~A})$ for all $\mathrm{A}, \mathrm{B} \in \operatorname{IFS}(X)$,

(S3) $\mathrm{S}_{1}(\mathrm{~A}, \mathrm{~A})=1$ for all $\mathrm{A} \in \operatorname{IFS}(X)$,

(S4) For all A,B, $\mathrm{C} \in \operatorname{IFS}(X)$. If $A \subseteq B \subseteq C$ then, we have

$$
\mathrm{S}_{1}(A, C) \leq \min \left\{\mathrm{S}_{1}(A, B), \mathrm{S}_{1}(B, C)\right\} .
$$

It means that

$$
\mathrm{S}_{1}(A, B)=\sum_{i=1}^{n} \omega_{i} \frac{S_{i}^{\mu}(A, B)+S_{i}^{v}(A, B)}{2}
$$

is a similarity measure of two intuitionistic fuzzy sets.

\section{Proof.}

From Proposition 1, we have:

(S1) Since $0 \leq S_{i}^{\mu}(A, B), S_{i}^{v}(A, B) \leq 1$, we have 


$$
0 \leq \mathrm{S}_{1}(A, B)=\sum_{i=1}^{n} \omega_{i} \frac{S_{i}^{\mu}(A, B)+S_{i}^{\nu}(A, B)}{2} \leq \sum_{i=1}^{n} \omega_{i}=1 .
$$

(S2). It is obviously.

(S3). If $\mathrm{A}=\mathrm{B}$, then $\mu_{A}\left(x_{i}\right)=\mu_{B}\left(x_{i}\right), v_{A}\left(x_{i}\right)=v_{B}\left(x_{i}\right)$, so that, we get

$S_{i}^{\mu}(A, B)=1, S_{i}^{\nu}(A, B)=1$. Hence $S_{1}(A, B)=\sum_{i=1}^{n} \omega_{i} \frac{S_{i}^{\mu}(A, B)+S_{i}^{\nu}(A, B)}{2}=\sum_{i=1}^{n} \omega_{i}=1$.

(S4). For all $A, B, C \in \operatorname{IFS}(X)$ such that $\mathrm{A} \subseteq \mathrm{B} \subseteq \mathrm{C}$, then we have

$$
S_{i}^{\mu}(A, C) \leq \min \left\{S_{i}^{\mu}(A, B), S_{i}^{\mu}(B, C)\right\}
$$

and

$$
S_{i}^{v}(A, C) \leq \min \left\{S_{i}^{v}(A, B), S_{i}^{v}(B, C)\right\}
$$

so that, we get

$$
\begin{gathered}
\mathrm{S}_{1}(A, B)=\sum_{i=1}^{n} \omega_{i} \frac{S_{i}^{\mu}(A, B)+S_{i}^{v}(A, B)}{2} \\
\leq \sum_{i=1}^{n} \omega_{i} \min \left\{\frac{S_{i}^{\mu}(A, B)+S_{i}^{v}(A, B)}{2}, \frac{S_{i}^{\mu}(B, C)+S_{i}^{v}(B, C)}{2}\right\} \\
=\min \left\{\mathrm{S}_{1}(\mathrm{~A}, \mathrm{~B}), \mathrm{S}_{1}(\mathrm{~B}, \mathrm{C})\right\} .
\end{gathered}
$$

More generally, with $p \in \mathrm{N}^{*}$, we have the similarity measures determined in definition 5.

Definition 4. A mapping $\mathrm{S}: \operatorname{IFS}(X) \times \operatorname{IFS}(X) \rightarrow[0,1]$ defined by

$$
\mathrm{S}_{p}^{\omega}(A, B)=\sum_{i=1}^{n} \omega_{i} \sqrt[p]{\frac{\left.S_{i}^{\mu}(A, B)\right)^{p}+\left(S_{i}^{\nu}(A, B)\right)^{p}}{2}}
$$

is the similarity measures of the intuitionistic fuzzy sets.

\section{Comparison with some existing similarity measures of IFS.}

Now, we remind some existing similarity measures on IFSs.

+ The cosine similarity measure proposed by (Ye, 2011) 


$$
\mathrm{C}_{Y}(\mathrm{~A}, \mathrm{~B})=\frac{1}{n} \sum_{i=1}^{n} \frac{\mu_{A}\left(x_{i}\right) \mu_{B}\left(x_{i}\right)+v_{A}\left(x_{i}\right) v_{B}\left(x_{i}\right)}{\sqrt{\mu_{A}^{2}\left(x_{i}\right)+v_{A}^{2}\left(x_{i}\right)} \sqrt{\mu_{B}^{2}\left(x_{i}\right)+v_{B}^{2}\left(x_{i}\right)}}
$$

+ The cosine similarity measure proposed by (Shi and Ye, 2013)

$$
\mathrm{C}_{S Y}(\mathrm{~A}, \mathrm{~B})=\frac{1}{n} \sum_{i=1}^{n} \frac{\mu_{A}\left(x_{i}\right) \mu_{B}\left(x_{i}\right)+v_{A}\left(x_{i}\right) v_{B}\left(x_{i}\right)+\pi_{A}\left(x_{i}\right) \pi_{B}\left(x_{i}\right)}{\sqrt{\mu_{A}^{2}\left(x_{i}\right)+v_{A}^{2}\left(x_{i}\right)+\pi_{A}^{2}\left(x_{i}\right)} \sqrt{\mu_{B}^{2}\left(x_{i}\right)+v_{B}^{2}\left(x_{i}\right)+\pi_{B}^{2}\left(x_{i}\right)}}
$$

+ The similarity measure based on the cotangent function introduced by (Tian, 2013)

$$
C T_{1}(A, B)=\frac{1}{n} \sum_{i=1}^{n} \cot \left[\frac{\pi}{4}+\frac{\pi}{4} \max \left(\begin{array}{l}
\left|\mu_{A}\left(x_{i}\right)-\mu_{B}\left(x_{i}\right)\right|, \\
\left|v_{A}\left(x_{i}\right)-v_{B}\left(x_{i}\right)\right|
\end{array}\right)\right]
$$

+ The similarity measure based on the cotangent function given by (Rajarajeswari and Uma, 2013)

$$
C T_{2}(A, B)=\frac{1}{n} \sum_{i=1}^{n} \cot \left[\frac{\pi}{4}+\frac{\pi}{4} \max \left(\begin{array}{l}
\left|\mu_{A}\left(x_{i}\right)-\mu_{B}\left(x_{i}\right)\right|, \\
\left|v_{A}\left(x_{i}\right)-v_{B}\left(x_{i}\right)\right|, \\
\left|\pi_{A}\left(x_{i}\right)-\pi_{B}\left(x_{i}\right)\right|
\end{array}\right)\right]
$$

+ The similarity measure based on the cosine function defined by (Ye, 2016).

$$
C S_{1}(A, B)=\frac{1}{n} \sum_{i=1}^{n} \cos \left[\frac{\pi}{2} \max \left(\begin{array}{l}
\left|\mu_{A}\left(x_{i}\right)-\mu_{B}\left(x_{i}\right)\right|, \\
\left|v_{A}\left(x_{i}\right)-v_{B}\left(x_{i}\right)\right|, \\
\left|\pi_{A}\left(x_{i}\right)-\pi_{B}\left(x_{i}\right)\right|
\end{array}\right)\right]
$$

+ The similarity measure based on the cosine function given by (Ye, 2016).

$$
C S_{2}(A, B)=\frac{1}{n} \sum_{i=1}^{n} \cos \left[\frac{\pi}{4}\left(\begin{array}{l}
\left|\mu_{A}\left(x_{i}\right)-\mu_{B}\left(x_{i}\right)\right| \\
+\left|v_{A}\left(x_{i}\right)-v_{B}\left(x_{i}\right)\right| \\
+\left|\pi_{A}\left(x_{i}\right)-\pi_{B}\left(x_{i}\right)\right|
\end{array}\right)\right]
$$

+ The similarity measure proposed by (Xu and Chen, 2008):

$$
S_{X C}(A, B)=1-\frac{1}{n} \sum_{i=1}^{n}\left[\frac{\left|\mu_{A}\left(x_{i}\right)-\mu_{B}\left(x_{i}\right)\right|+\left|v_{A}\left(x_{i}\right)-v_{B}\left(x_{i}\right)\right|}{4}+\frac{1}{2} \max \left(\begin{array}{l}
\left|\mu_{A}\left(x_{i}\right)-\mu_{B}\left(x_{i}\right)\right|, \\
\left|v_{A}\left(x_{i}\right)-v_{B}\left(x_{i}\right)\right|
\end{array}\right)\right]
$$


+ The similarity measures given by (Papakostas et al., 2013)

$$
S_{P 1}(A, B)=1-\frac{1-\exp \left(-\frac{1}{2} \sum_{i=1}^{n}\left|\mu_{A}\left(x_{i}\right)-\mu_{B}\left(x_{i}\right)\right|+\left|v_{A}\left(x_{i}\right)-v_{B}\left(x_{i}\right)\right|\right)}{1-\exp (-n)}
$$

and

$$
S_{P 2}(A, B)=1-\frac{1-\exp \left(-\frac{1}{2} \sum_{i=1}^{n}\left|\sqrt{\mu_{A}\left(x_{i}\right)}-\sqrt{\mu_{B}\left(x_{i}\right)}\right|+\mid \sqrt{v_{A}\left(x_{i}\right)}-\sqrt{v_{B}\left(x_{i}\right)}\right)}{1-\exp (-\mathrm{n})}
$$

+ The similarity measure introduced by of (Song et al., 2015)

$$
S_{S}(A, B)=\frac{1}{2 n} \sum_{i=1}^{n}\left[\sqrt{\mu_{A}\left(u_{i}\right) \mu_{B}\left(u_{i}\right)}+2 \sqrt{v_{A}\left(u_{i}\right) v_{B}\left(u_{i}\right)}+\sqrt{\pi_{A}\left(u_{i}\right) \pi_{B}\left(u_{i}\right)}+\sqrt{\left(1-v_{A}\left(u_{i}\right)\right)\left(1-v_{B}\left(u_{i}\right)\right)}\right]
$$

+ The similarity measure introduced by of (Song et al., 2019)

$S_{S 1}(A, B)=\frac{1}{3 n} \sum_{i=1}^{n}\left[2 \sqrt{\mu_{A}\left(u_{i}\right) \mu_{B}\left(u_{i}\right)}+2 \sqrt{v_{A}\left(u_{i}\right) v_{B}\left(u_{i}\right)}+\sqrt{\pi_{A}\left(u_{i}\right) \pi_{B}\left(u_{i}\right)}+\sqrt{\left(1-\mu_{A}\left(u_{i}\right)\right)\left(1-\mu_{B}\left(u_{i}\right)\right)}+\sqrt{\left(1-v_{A}\left(u_{i}\right)\right)\left(1-v_{B}\left(u_{i}\right)\right)}\right]$

We compare our proposed similarity measure with the above existing similarity measures with numerical examples of the recognition problems as follows.

Example 1. Suppose that $A$ and $B$ are two given patterns in form IFSs in $X=\{x\}$ as follows: $A=\{(x, 0,1)\}, B=\{(x, 0,0))\}$ and a new sample $C=\{(x, 1,0)\}$.

\section{Question: What pattern does we can put $C$ belong to?}

In this case, we can use the similarity measures to answer this question. If $S(A, C)<S(\mathrm{~B}, \mathrm{C})$ then we put $C$ belongs to class of $B$, reverse, if $S(A, C)>S(\mathrm{~B}, \mathrm{C})$ then we put $C C$ belongs to class of $A$. Results in Table 1 indicate that our proposed measures and the similarity measures $S_{P 1}, S_{P 2}, S_{X C}, S_{S}$ and $S_{S 1}$ show that $C$ belongs to class of $B$, other similarity measures do not give out the classification results. It means, in this case, the similarity obtained is better than that of other measures $\mathrm{C}_{Y}, \mathrm{C}_{S Y}, C T_{1}, C T_{2}, C S_{1}$ and $C S_{2}$.

Table 1. The classification results in example 1.

\begin{tabular}{|l|c|c|l|}
\hline Similarity measures & $S(A, C)$ & $S(B, C)$ & The classification results \\
\hline $\mathrm{C}_{Y}(\mathrm{Ye}, 2011)$ & 0 & Null & Null \\
\hline
\end{tabular}




\begin{tabular}{|l|c|c|l|}
\hline $\mathrm{C}_{S Y}$ (Shi and Ye, 2013) & 0 & 0 & Null \\
\hline$C T_{1}$ (Tian, 2013) & 0 & 0 & Null \\
\hline$C T_{2}$ (Rajarajeswari and Uma, 2013) & 0 & 0 & Null \\
\hline$C S_{1}$ (Ye, 2016) & 0 & 0 & Null \\
\hline$C S_{2}($ Ye, 2016) & 0 & 0 & Null \\
\hline$S_{P 1}$ (Papakostas et al., 2013) & 0 & 0.3775 & $C$ belongs to class of $B$ \\
\hline$S_{P 2}$ (Papakostas et al. , 2013) & 0 & 0.3775 & $C$ belongs to class of $B$ \\
\hline$S_{X C}$ (Xu and Chen, 2008) & 0 & 0.25 & $C$ belongs to class of $B$ \\
\hline$S_{S}$ (Song et al., 2015) & 0 & 0.5 & $C$ belongs to class of $B$ \\
\hline$S_{S 1}$ (Song et al., 2019) & 0 & 0.3333 & $C$ belongs to class of $B$ \\
\hline$S_{1}$ (proposed measure) & 0 & 0.5 & $C$ belongs to class of $B$ \\
\hline $\begin{array}{l}S_{2}^{\omega} \text { (proposed measure, in Eq.(2) } \\
\text { with } p=2 \text { ) }\end{array}$ & 0 & 0.7071 & $C$ belongs to class of $B$ \\
\hline
\end{tabular}

Null means that we can't determine where class $C$ belong to

Next, we consider the benefits of using our proposed similarity measures in the example of pattern recognition.

Example 2. Suppose that $A$ and $B$ are two patterns in form as IFSs in $X=\left\{x_{1}, x_{2}\right\}$ as follows:

$A=\left\{\left(x_{1}, 0.4,0.6\right),\left(x_{2}, 0.4,0.2\right)\right\}, B=\left\{\left(x_{1}, 0.2,0.8\right),\left(x_{2}, 0.1,0.5\right)\right\}$.

We have a new sample $C=\left\{\left(x_{1}, 0.3,0.7\right),\left(x_{2}, 0.2,0.3\right)\right\}$.

\section{Question: What pattern does $C$ belong to?}

Results in Table 2 indicate that our proposed measures and the similarity measures $\mathrm{C}_{Y}, \mathrm{C}_{S Y}$ show that $C$ belongs to class of $B$, similarity measures $S_{S}, S_{P 2}$ show that $C$ belongs to class of $A$, similarity measures in $C T_{1}, C T_{2}, C S_{1}, C S_{2}, S_{P 1}, S_{X C}$ do not give out the classification results. In this example, there are five measures show that $C$ belongs to class of $B$, and only two measures show that $C$ belongs to class of $A$. So that, we can put $C$ belongs to class of $B$ (see Table 2). It means, in this 
case, the similarity obtained is better than that of other measures $C T_{1}, C T_{2}, C S_{1}$, $C S_{2}, S_{P 1}, S_{X C}$.

Table 2. The classification results in example 2.

\begin{tabular}{|l|l|c|l|}
\hline Similarity measures & $S(A, C)$ & $S(B, C)$ & The classification results \\
\hline $\mathrm{C}_{Y}$ (Ye, 2011) & 0.9258 & 0.9560 & $C$ belongs to class of $B$ \\
\hline $\mathrm{C}_{S Y}$ (Shi and Ye, 2013) & 0.8486 & 0.9567 & $C$ belongs to class of $B$ \\
\hline$C T_{1}$ (Tian, 2013) & 0.7903 & 0.7903 & Null \\
\hline $\begin{array}{l}C T_{2} \text { (Rajarajeswari and Uma, } \\
2013)\end{array}$ & 0.7903 & 0.7903 & Null \\
\hline$C S_{1}$ (Ye, 2016) & 0.9694 & 0.9694 & Null \\
\hline$C S_{2}$ (Ye, 2016) & 0.9694 & 0.9694 & Null \\
\hline$S_{P 1}$ (Papakostas et al., 2013) & 0.8145 & 0.8145 & Null \\
\hline$S_{P 2}$ (Papakostas et al. , 2013) & 0.7413 & 0.5841 & $C$ belongs to class of $A$ \\
\hline$S_{X C}$ (Xu and Chen, 2008) & 0.8625 & 0.8625 & Null \\
\hline$S_{S}$ (Song et al., 2015) & 0.9893 & 0.9854 & $C$ belongs to class of $A$ \\
\hline$S_{S 1}$ (Song et al., 2019) & 0.9681 & 0.9714 & $C$ belongs to class of $B$ \\
\hline$S_{1}$ (proposed measure) & 0.8407 & 0.8497 & $C$ belongs to class of $B$ \\
\hline $\begin{array}{l}S_{2}^{\omega} \text { (proposed measure, in Eq.(2) } \\
\text { with } p=2 \text { ) }\end{array}$ & 0.8435 & 0.8501 & $C$ belongs to class of $B$ \\
\hline
\end{tabular}

Null means that we can't determine where class $C$ belong to

Here, we get the result that we can make $C$ belong to pattern $A$. We find that the components $S_{i}^{v}(A, B)=1-\left|v_{A}\left(x_{i}\right)-v_{B}\left(x_{i}\right)\right|(i=1,2)$ in our proposed similarity measure have great influence on $S(A, B)$. It means that for three sets $A, B$ and $C \in I F S(X)$, if $S_{i}^{v}(A, B) \geq S_{i}^{v}(A, C)$ then $S(A, B) \geq S(A, C)$. In this case, $S_{1}^{v}(A, C)=$ $S_{1}^{V}(B, C)=0.9$ and $S_{2}^{v}(B, C)=0.8<S_{2}^{v}(A, C)=1$. These are also reasonable. 


\section{New entropy of intuitionistic fuzzy sets}

Entropy of intuitionistic fuzzy set used to measure the intuition of the intuitionistic fuzzy sets. In 2001, Szmidt E and Kacprzyk introduce the concept of entropy of intuitionistic fuzzy set.

Definition 5 (Szmidt and Kacprzyk, 2001). An entropy on $\operatorname{IFS}(X)$ is a function $E: \operatorname{IFS}(X) \rightarrow[0,1]$, satisfying all following conditions

(E1) $E(A)=0$ if $A \in \operatorname{IFS}(X)$ has $\mu_{A}\left(x_{i}\right), v_{A}\left(x_{i}\right) \in\{0,1\}$ for all $x_{i} \in X$.

(E2) $E(A)=1$ if only if $\mu_{A}\left(x_{i}\right)=v_{A}\left(x_{i}\right)$ for all $x_{i} \in X$,

(E3) $E(A)=E\left(A^{C}\right)$, for all $A \in \operatorname{IFS}(X)$.

(E4) $E(A) \leq E(B)$ for all $A, B \in \operatorname{IFS}(X)$ satisfy either if $\mu_{A}\left(x_{i}\right) \leq \mu_{B}\left(x_{i}\right)$ $\leq v_{B}\left(x_{i}\right) \leq v_{A}\left(x_{i}\right)$ or $\mu_{A}\left(x_{i}\right) \geq \mu_{B}\left(x_{i}\right) \geq v_{B}\left(x_{i}\right) \geq v_{A}\left(x_{i}\right)$ for all $x_{i} \in X$.

Definition 7. A mapping E: $\operatorname{IFS}(X) \rightarrow[0,1]$ is defined by

$$
E_{T}(A)=\frac{1}{2 n} \sum_{i=1}^{n}\left[\frac{e^{-\mid \mu_{A}\left(x_{i}\right)-v_{A}\left(x_{i}\right)}-e^{-1}}{1-e^{-1}}+\left(1-\left|\mu_{A}\left(x_{i}\right)-v_{A}\left(x_{i}\right)\right|\right)\right]
$$

Remark. We easy verify that $E_{T}(A)=\mathrm{S}_{1}\left(A, A^{C}\right)$ for all $A \in \operatorname{IFS}(X)$.

Theorem 2. Let $A$ an arbitrary IFS in $X$. The function $E_{T}(A)$ in the eq. (4) is an entropy on $\operatorname{IF} S(X)$.

Proof.

(E1) If $A \in \operatorname{IFS}(X)$ having $\mu_{A}\left(x_{i}\right), v_{A}\left(x_{i}\right) \in\{0,1\}$ then $\left|\mu_{A}\left(x_{i}\right)-v_{A}\left(x_{i}\right)\right|=1$, for all $x_{i} \in X$. It means that $E_{T}(A)=0$.

(E2) It is obviously.

(E3) It is obviously.

(E4) For all $A, B \in I F S(X)$ satisfy either if $\mu_{A}\left(x_{i}\right) \leq \mu_{B}\left(x_{i}\right) \leq v_{B}\left(x_{i}\right) \leq v_{A}\left(x_{i}\right)$ or $\mu_{A}\left(x_{i}\right)$ $\geq \mu_{B}\left(x_{i}\right) \geq v_{B}\left(x_{i}\right) \geq v_{A}\left(x_{i}\right)$ for all $x_{i} \in X$, then $-\left|\mu_{A}\left(x_{i}\right)-v_{A}\left(x_{i}\right)\right| \leq-\left|\mu_{B}\left(x_{i}\right)-v_{B}\left(x_{i}\right)\right|$ for 
all $x_{i} \in X$. This implies that $E(A) \leq E(B)$ for all $A, B \in I F S(X)$ satisfy either if $\mu_{A}\left(x_{i}\right) \leq \mu_{B}\left(x_{i}\right) \leq v_{B}\left(x_{i}\right) \leq v_{A}\left(x_{i}\right)$ or $\mu_{A}\left(x_{i}\right) \geq \mu_{B}\left(x_{i}\right) \geq v_{B}\left(x_{i}\right) \geq v_{A}\left(x_{i}\right)$ for all $x_{i} \in X$.

\section{Compare to some existing other entropies.}

We consider the comparison of six entropies via examples as follows.

Example 3. Let $\mathrm{A}=\left\{\left(\mathrm{x}_{6}, 0.2,0.8\right),\left(\mathrm{x}_{7}, 0.3,0.5\right),\left(\mathrm{x}_{8}, 0.6,0.4\right),\left(\mathrm{x}_{9}, 0.9,0\right),\left(\mathrm{x}_{10}, 1,0\right)\right\}$ be a PFS on the universal set $X=\left\{x_{6}, x_{7}, x_{8}, x_{9}, x_{10}\right\}$, where $x_{i}$ is an apartment having $i$ rooms. In the characterizations of the linguistic variables, we regard A as "Large" then according to the operator law in the eq.(1) we have $\mathrm{A}^{0.5}$ may be regarded as "Quite Large", $\mathrm{A}^{2}$ may be regarded as "Very Large", $\mathrm{A}^{3}$ may be regarded as "Quite Very Large", $\mathrm{A}^{4}$ may be regarded as "Very Very Large", in which

$$
\begin{aligned}
& \mathrm{A}^{0.5}=\left\{\left(\mathrm{x}_{6}, 0.4472,0.5528\right),\left(\mathrm{x}_{7}, 0.5477,0.2929\right),\left(\mathrm{x}_{8}, 0.7746,0.2254\right),\left(\mathrm{x}_{9}, 0.9486,0\right),\left(\mathrm{x}_{10}, 1,0\right)\right\}, \\
& \mathrm{A}^{2}=\left\{\left(\mathrm{x}_{6}, 0.04,0.96\right),\left(\mathrm{x}_{7}, 0.09,0.75\right),\left(\mathrm{x}_{8}, 0.36,0.64\right),\left(\mathrm{x}_{9}, 0.81,0\right),\left(\mathrm{x}_{10}, 1,0\right)\right\}, \\
& \mathrm{A}^{3}=\left\{\left(\mathrm{x}_{6}, 0.008,0.992\right),\left(\mathrm{x}_{7}, 0.027,0.875\right),\left(\mathrm{x}_{8}, 0.216,0.784\right),\left(\mathrm{x}_{9}, 0.729,0\right),\left(\mathrm{x}_{10}, 1,0\right)\right\}, \\
& \mathrm{A}^{3}=\left\{\left(\mathrm{x}_{6}, 0.0016,0.9984\right),\left(\mathrm{x}_{7}, 0.0081,0.9375\right),\left(\mathrm{x}_{8}, 0.1296,0.8704\right),\left(\mathrm{x}_{9}, 0.6561,0\right),\left(\mathrm{x}_{10}, 1,0\right)\right\}
\end{aligned}
$$

Based on the mathematical view and intuitive of human, we easy to see that $\mathrm{A}^{m+1} \subset \mathrm{A}^{m}(m>0)$ and $\lim _{m \rightarrow+\infty} \mathrm{A}^{m}=\varnothing=\left\{\left(x_{1}, 0,1\right),\left(x_{2}, 0,1\right)\right\}$. So that the entropy measure $E$ must be satisfied $E(A)>E\left(A^{2}\right)>E\left(A^{3}\right)>E\left(A^{4}\right)$. According to Table 1, we find that six entropy measures of picture fuzzy sets satisfy this statement. To do this, we revisit some entropies on the fuzzy intuitionistic sets.

- Entropy of (Burillo and Bustince, 1996) $E_{B B}(A)=\frac{1}{n} \sum_{i=1}^{n} \pi_{A}\left(x_{i}\right)$

- Entropy of (Szmidt and Kacprzyk, 2001)

$$
\mathrm{E}_{S K}(\mathrm{~A})=\frac{1}{n} \sum_{i=1}^{n} \frac{\max \operatorname{count}\left(\mathrm{A}\left(x_{i}\right) \cap \mathrm{A}^{C}\left(x_{i}\right)\right)}{\max \operatorname{count}\left(\mathrm{A}\left(x_{i}\right) \cup \mathrm{A}^{C}\left(x_{i}\right)\right)}
$$


where max count $\left(\mathrm{A}\left(x_{i}\right)\right)=\mu_{A}\left(x_{i}\right)+\pi_{A}\left(x_{i}\right)$ for all $x_{i} \in X$.

- Entropy of (Hung and Yang, 2006)

$$
E_{H}(A)=\frac{1}{n(1-\beta)} \sum_{i=1}^{n} \log \left[\mu_{A}^{\beta}\left(x_{i}\right)+v_{A}^{\beta}\left(x_{i}\right)+\pi_{A}^{\beta}\left(x_{i}\right)\right]
$$

where $0<\beta<1$.

- Entropy of (Vlachos and Sergiagis,2007)

$$
E_{V S}(A)=-\frac{1}{n \ln 2} \sum_{i=1}^{n}\left[\begin{array}{l}
\mu_{A}\left(x_{i}\right) \ln \mu_{A}\left(x_{i}\right)+v_{A}\left(x_{i}\right) \ln v_{A}\left(x_{i}\right) \\
-\left(1-\pi_{A}\left(x_{i}\right)\right) \ln \left(1-\pi_{A}\left(x_{i}\right)\right)-\pi_{A}\left(x_{i}\right) \ln 2
\end{array}\right]
$$

- Entropy of (Ye, 2010)

$$
E_{Y}(A)=\frac{1}{n(\sqrt{2}-1)} \sum_{i=1}^{n}\left[\cos \frac{\pi\left(1-\mu_{A}\left(x_{i}\right)+v_{A}\left(x_{i}\right)\right)}{4}+\cos \frac{\pi\left(1+\mu_{A}\left(x_{i}\right)-v_{A}\left(x_{i}\right)\right)}{4}-1\right] .
$$

- Entropy of (Zhang and Jiang, 2008)

$$
E_{\text {ZJ }}(A)=\frac{1}{n} \sum_{i=1}^{n} \frac{\mu_{A}\left(x_{i}\right) \wedge v_{A}\left(x_{i}\right)}{\mu_{A}\left(x_{i}\right) \vee v_{A}\left(x_{i}\right)} .
$$

- Entropy of (Zhu and Li, 2016)

$$
E_{\text {ZL }}(A)=\frac{1}{4 n} \sum_{i=1}^{n}\left[\left(1+\pi_{A}\left(x_{i}\right)\right)\left(1-\left|\mu_{A}\left(x_{i}\right)-v_{A}\left(x_{i}\right)\right|\right)+\pi_{A}\left(x_{i}\right)\right] .
$$

The results of six entropy measures $E_{T}, E_{B B}, E_{S K}, E_{H}, E_{Y}, E_{\text {ZJ }}$ and $E_{\text {ZL }}$ shown in the Table 3.

Table 3. Comparison of the degree of fuzziness with entropy measures

\begin{tabular}{|l|l|l|l|l|l|l|l|l|}
\hline & $E_{T}$ & $E_{B B}$ & $E_{S K}$ & $E_{H}$ & $E_{V S}$ & $E_{Y}$ & $E_{Z J}$ & $E_{Z L}$ \\
\hline $\mathrm{A}^{0.5}$ & $\mathbf{0 . 3 9 8 9}$ & 0.0421 & $\mathbf{0 . 3 2 7 0}$ & 0.2346 & $\mathbf{0 . 4 7 1 6}$ & 0.5406 & $\mathbf{0 . 4 0 8 7}$ & 0.1237 \\
\hline $\mathrm{A}$ & $\mathbf{0 . 3 8 7 4}$ & 0.0600 & $\mathbf{0 . 3 0 3 3}$ & 0.2436 & $\mathbf{0 . 4 6 0 1}$ & 0.5452 & $\mathbf{0 . 3 7 9 2}$ & 0.1285 \\
\hline $\mathrm{A}^{2}$ & $\mathbf{0 . 2 3 5 0}$ & 0.0700 & $\mathbf{0 . 1 4 4 8}$ & 0.2154 & $\mathbf{0 . 2 5 1 9}$ & 0.3896 & $\mathbf{0 . 1 8 1 0}$ & 0.0885 \\
\hline $\mathrm{A}^{3}$ & $\mathbf{0 . 1 4 7 2}$ & 0.0738 & $\mathbf{0 . 0 6 2 9}$ & 0.1817 & $\mathbf{0 . 1 4 4 6}$ & 0.2844 & $\mathbf{0 . 0 7 8 6}$ & 0.0664 \\
\hline $\mathrm{A}^{4}$ & $\mathbf{0 . 1 1 3 2}$ & 0.0797 & $\mathbf{0 . 0 3 1 8}$ & 0.1538 & $\mathbf{0 . 1 0 6 1}$ & 0.2262 & $\mathbf{0 . 0 3 9 8}$ & 0.0599 \\
\hline
\end{tabular}

"bold" means that the entropy values are sensible 


\section{Application of similarity measures and entropy in a software quality model}

There are some models for evaluating software quality, such as the software quality evaluation model generated using the hesitant fuzzy uncertain linguistic information ( $\mathrm{Li}$ et al., 2014) or the model based on the fuzzy analytic hierarchy process (Chang et al., 2008). These models are quite complex because they either require building linguistic variables ( $\mathrm{Li}$ et al., 2014) or require using primitive ISO standards published in 2001 (Chang et al., 2008). In this section, we constructed a MCDM model based on the proposed similarity measures (in section 3) and entropy (in section 4) to evaluate the quality of software projects. Software is an important factor in the development of computers. Efficient orchestrated software enables applications solving real-world problems more effectively. Software engineers often focus on software production. Good-quality software that can keep up with budget constraints and time is considered to be effective software. In 2011, ISO defined a new standard ISO 25010 to evaluate system and software product quality. This standard confirmed in (IOS, 2017) and included the following key quality identifiers.

- Functional Suitability $C_{1}$

- Functional Correctness $C_{2}$

- Testability $C_{3}$

- Performance Efficiency $C_{4}$

- Compatibility $C_{5}$

- Usability $C_{6}$

- Appropriateness Recognizability $C_{7}$

- User Interface Aesthetics $C_{8}$

- Reliability $C_{9}$

- Security $C_{10}$

- Maintainability $C_{11}$

- Modifiability $C_{12}$

- Portability $C_{13}$ 
In the quality evaluation of software projects, the quality of software projects is compared with the best example based on a set of criteria (i.e., one that matches all criteria). For the criterion of benefits, being the best is often desirable. However, for the criterion of cost, having the lowest cost is usually desirable. Quality evaluation is an MCDM problem. Moreover, the digitization of qualitative criteria is highly dependent on human psychology. The theory of IFSs is more useful for solving uncertainty problems. Therefore, we proposed an MCDM model for evaluating software quality by using an IFS similarity measure, namely the intuitionistic fuzzy software quality model.

\section{The IFSQM has seven steps as follows:}

1. Determine the criteria for quality assessment $C_{j},(j=1,2, \ldots, n)$

2. Identify different projects for evaluation $P_{i},(i=1,2, \ldots, m)$

3. Determine the intuitionistic fuzzy sets $P_{i}=\left\{\left(C_{j}, \mu_{\mathrm{ij}}, v_{\mathrm{ij}}\right) \mid C_{j} \in U\right\}$ for $i=1,2, \ldots, m$. We consider that $P_{i} \quad(i=1,2, \ldots, m)$ is an intuitionistic fuzzy set on the universal set $U=\left\{C_{1}, C_{2}, \ldots, C_{n}\right\}$

4. Determine the weight $\omega_{j}$ of the criteria $C_{j}(j=1,2, \ldots, n)$. In this step, we consider $C_{j}=\left\{\left(P_{i}, \mu_{i j}, v_{i j}\right) \mid P_{i} \in P\right\}$ is an intuitionistic set on $P=\left\{P_{1}, P_{2}, \ldots, P_{n}\right\}$. We denote $e_{j}=e\left(C_{j}\right)$, then we can determine the weight

$$
\omega_{j}=\frac{1-e_{j}}{n-\sum_{j=1}^{n} e_{j}}
$$

for all $C_{j}(j=1,2, \ldots, n)$.

5. Build the best project $P_{\mathrm{b}}$ : cost criteria are $(0,1)$ and benefit criteria are $(1,0)$. We consider that $P_{\mathrm{b}}$ is an intuitionistic fuzzy set on the universal set $U=\left\{C_{1}, C_{2}, \ldots, C_{n}\right\}$

6. Calculate the similarity measure $S\left(P_{i}, P_{b}\right)$ of each project $P_{i} \quad(i=1,2, \ldots, m)$ with the best project. 
7. Rank projects based on the similarity measure. The project $P_{i}$ is better than the project $P_{k}$ (we denote $P_{i} \mathrm{f} P_{k}$ ) if $S\left(P_{i}, P_{b}\right)>S\left(P_{k}, P_{b}\right), i=1,2, \ldots, m$ and $k=1,2, \ldots, m$.

This algorithm consists of simple computation steps on fuzzy decision-making matrix IF with $m$ rows and $n$ columns (corresponding to $m$ alternatives and $n$ criteria). So we can define its computational complexity as just $O(m n)$ polynomial time.

Example 4. We consider the IFSQM to evaluate the software quality of five software projects: $P_{1}, P_{2}, P_{3}, P_{4}$ and $P_{5}$. The software quality criteria are $U=\left\{C_{1}, C_{2}\right.$ $\left., C_{3}, C_{4}, C_{5}, C_{6}, C_{7}, C_{8}, C_{9}, C_{10}, C_{11}, C_{12}, C_{13}\right\}$. In this model, we consider $P_{i}$ $(i=1,2, \ldots, m)$ are the intuitionistic fuzzy sets on $U$. Then, we have an intuitionistic fuzzy decision matrix of software based on software quality criteria (Table 4). These are also step 1, step 2 and step 3 of IFSQM.

Step 4. We compute the weight of each $C_{j}(j=1,2, \ldots, n)$ based on the eq. (5), then the weigh vector of criteria as follows:

$\omega=(0.062,0.1,0.097,0.12,0.063,0.07,0.072,0.097,0.063,0.072,0.06,0.068,0.065)$

Step 5. Building the best project: In this example, all the software quality criteria used for evaluation are the criteria of benefit. Therefore, we chose the best project is $P_{\mathrm{b}}=\left\{\left(C_{i}, 1,0\right) \mid i=1,2, \ldots, 13\right\}$.

Step 6. The similarity measures of each project with the best project is shown in Table 5 and Table 6.

Step 7. Ranking projects are shown in Table 5 and Table 6.

We denote IFSQM 1 and IFSQM 1 as versions of IFSQM when using the similarity measure in step 6 by equation (2) and equation (3) with $p=2$, respectively.

Table 4. The intuitionistic fuzzy decision matrix of software based on software quality criteria

\begin{tabular}{|l|l|l|l|l|l|}
\hline & $P_{1}$ & $P_{2}$ & $P_{3}$ & $P_{4}$ & $P_{5}$ \\
\hline
\end{tabular}




\begin{tabular}{|c|c|c|c|c|c|}
\hline$C_{1}$ & $(0.49,0.1)$ & $(0.6,0.04)$ & $(0.36,0.04)$ & $(0.81,0.05)$ & $(0.25,0.25)$ \\
\hline$C_{2}$ & $(0.7,0.16)$ & $(0.8,0.01)$ & $(0.73,0.03)$ & $(06,0.11)$ & $(0.81,0.05)$ \\
\hline$C_{3}$ & $(0.8,0.1)$ & $(0.8,0.01)$ & $(1,0)$ & $(0.49,0.19)$ & $(0.64,0.1)$ \\
\hline$C_{4}$ & $(0.81,0.05)$ & $(0.9,0.1)$ & $(1,0)$ & $(0.8,0.01)$ & $(0.81,0.05)$ \\
\hline$C_{5}$ & $(1,0)$ & $(0.25,0.1)$ & $(1,0)$ & $(0.25,0.3)$ & $(0.25,0.3)$ \\
\hline$C_{6}$ & $(0.25,0.4)$ & $(1,0)$ & $(1,0)$ & $(0.25,0.16)$ & $(0.25,0.4)$ \\
\hline$C_{7}$ & $(0.25,0.4)$ & $(0.6,0.04)$ & $(1,0)$ & $(0.16,0.18)$ & $(0.81,0.05)$ \\
\hline$C_{8}$ & $(0.8,0.1)$ & $(0.8,0)$ & $(1,0)$ & $(0.49,0.19)$ & $(0.64,0.1)$ \\
\hline$C_{9}$ & $(1,0)$ & $(0.25,0.1)$ & $(1,0)$ & $(0.25,0.3)$ & $(0.25,0.3)$ \\
\hline$C_{10}$ & $(0.25,0.4)$ & $(0.6,0.04)$ & $(1,0)$ & $(0.16,0.176)$ & $(0.81,0.05)$ \\
\hline$C_{11}$ & $(0.49,0.1)$ & $(0.6,0.04)$ & $(0.36,0.04)$ & $(0.81,0.05)$ & $(0.25,0.25)$ \\
\hline$C_{12}$ & $(0.25,0.4)$ & $(1,0)$ & $(1,0)$ & $(0.25,0.16)$ & $(0.25,0.4)$ \\
\hline$C_{13}$ & $(0.3,0.4)$ & $(1,0)$ & $(1,0)$ & $(0.25,0.16)$ & $(0.25,0.4)$ \\
\hline
\end{tabular}

Evaluation of the quality of the product based on similarity measures is carried out in accordance with the following principles. If $0<S\left(P_{i}, P_{b}\right)<0.5$ then the project $P_{i}$ belongs to the class Low $(\mathrm{L})$; if $0.5 \leq S\left(P_{i}, P_{b}\right)<0.75$ then the project $P_{i}$ belongs to the class Medium $(\mathrm{M})$; if $0.75 \leq S\left(P_{i}, P_{b}\right)<0.9$ then the project $P_{i}$ belongs to the class High $(\mathrm{H})$; if $0.9 \leq S\left(P_{i}, P_{b}\right)<1$ then the project $P_{i}$ belongs to the class Very $\operatorname{High}(\mathrm{VH})$. 
Accordingly, we can see that the rank of project $P_{3}$ is the maximum and its quality is Very High. The second is project $P_{2}$ which has its quality High. Three projects $P_{1}, P_{4}$ and $P_{5}$ have their quality being Medium, simultaneously ranked $3^{\text {rd }}, 4^{\text {th }}$ and $5^{\text {th }}$, respectively.

Table 5. The quality of software projects using IFSQM1

\begin{tabular}{|l|c|c|c|c|c|}
\hline Software projects & $P_{1}$ & $P_{2}$ & $P_{3}$ & $P_{4}$ & $P_{5}$ \\
\hline Similarity values & 0.6988 & 0.8541 & 0.9510 & 0.6954 & 0.6680 \\
\hline Ranking & 3 & 2 & 1 & 4 & 5 \\
\hline Quality & $\mathrm{M}$ & $\mathrm{H}$ & $\mathrm{VH}$ & $\mathrm{M}$ & $\mathrm{M}$ \\
\hline
\end{tabular}

Table 6. The quality of software projects using IFSQM2

\begin{tabular}{|l|c|c|c|c|c|}
\hline Software projects & $P_{1}$ & $P_{2}$ & $P_{3}$ & $P_{4}$ & $P_{5}$ \\
\hline Similarity values & 0.6753 & 0.8305 & 0.9400 & 0.6543 & 0.6381 \\
\hline Ranking & 3 & 2 & 1 & 4 & 5 \\
\hline Quality & $\mathrm{M}$ & $\mathrm{H}$ & $\mathrm{VH}$ & $\mathrm{M}$ & $\mathrm{M}$ \\
\hline
\end{tabular}

To further demonstrate the feasibility of the proposed method, we compare the ranking results with some existing ranking methods in (Song et al., 2015; Ye,2016; Zhou, 2016; Thao and Duong, 2019; Song et al., 2019; Quynh et al., 2020; Thao ${ }^{\mathrm{a}}$, 2021). The comparison results are shown in Figure 1. According to Figure 1, we easy see that almost method is shown that: P3 is the highest, P 2 is the second, P3 is the third, P5 and P4 are in the $4^{\text {th }}$ and $5^{\text {th }}$ place, respectively. Therefore, this is the final ranking option. It also coincides with the ranking results of the proposed new method. This explains the effectiveness of our proposed methods. We also calculate some scenarios having small changes in the weight of the criteria. According to that, we compare the ranking results of the options based on these different methods to evaluate the stability of the proposed method. Figures 2 and 3 illustrate the ranking results of the alternatives when using weights $\omega_{2}=\left(\frac{1}{13}, \frac{1}{13}, \frac{1}{13}, \frac{1}{13}, \frac{1}{13}, \frac{1}{13}, \frac{1}{13}, \frac{1}{13}, \frac{1}{13}, \frac{1}{13}, \frac{1}{13}, \frac{1}{13}, \frac{1}{13}\right)$

and 
$\omega_{3}=(0.062,0.1,0.096,0.119,0.063,0.07,0.072,0.096,0.063,0.072,0.06,0.062,0.065)$, respectively. In these cases, we see that having a small change in the ranking results of P4 and P5 when using the ranking methods of (Ye, 2016), (Zhou, 2016) and (Quynh et al., 2020). The rankings of the other options still remain. Meanwhile, the proposed method along with the remaining methods (Song et al., 2015; Song et al., 2019; Thao and Duong, 2019; Thao, 2021) all give stable ranking results.

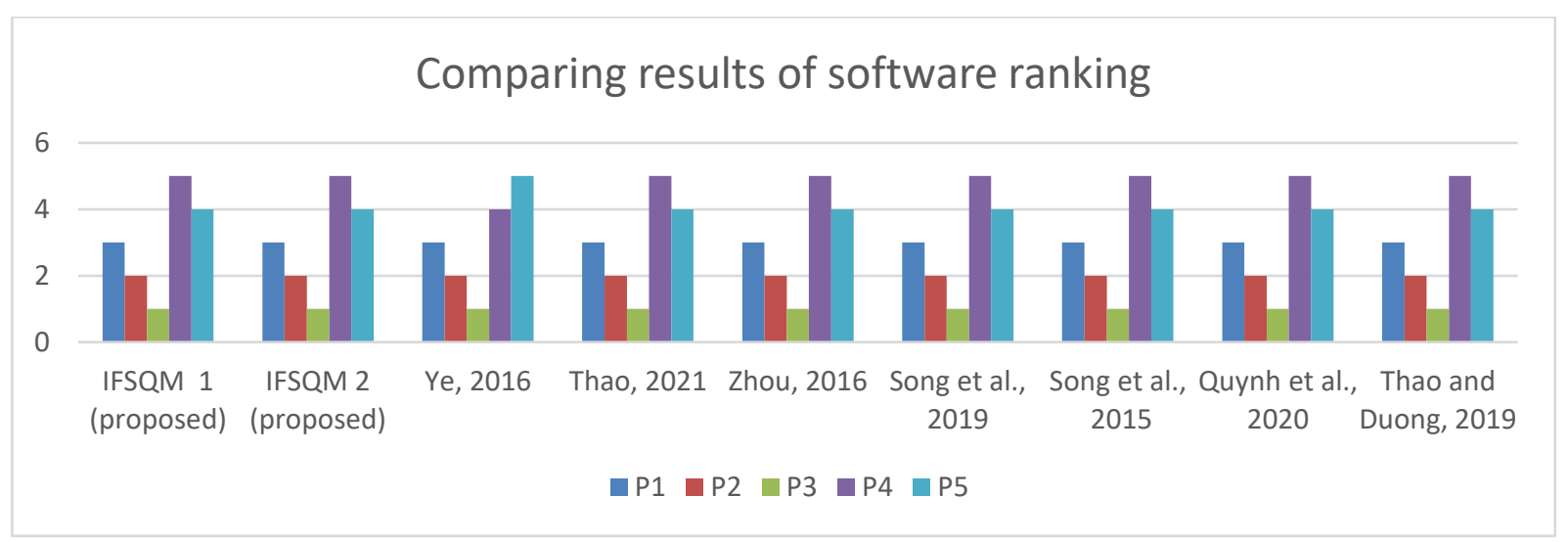

Figure 1. Comparing results of software raking.

Comparing results of software raking with weight 2

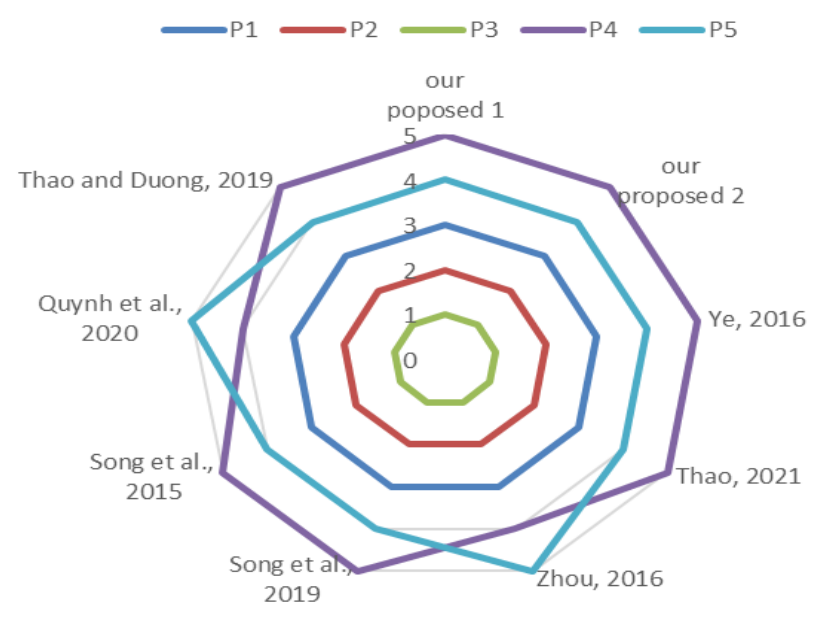

Figure 2. Comparing results of software raking with weight 2 
Comparing results of software raking with weight 2

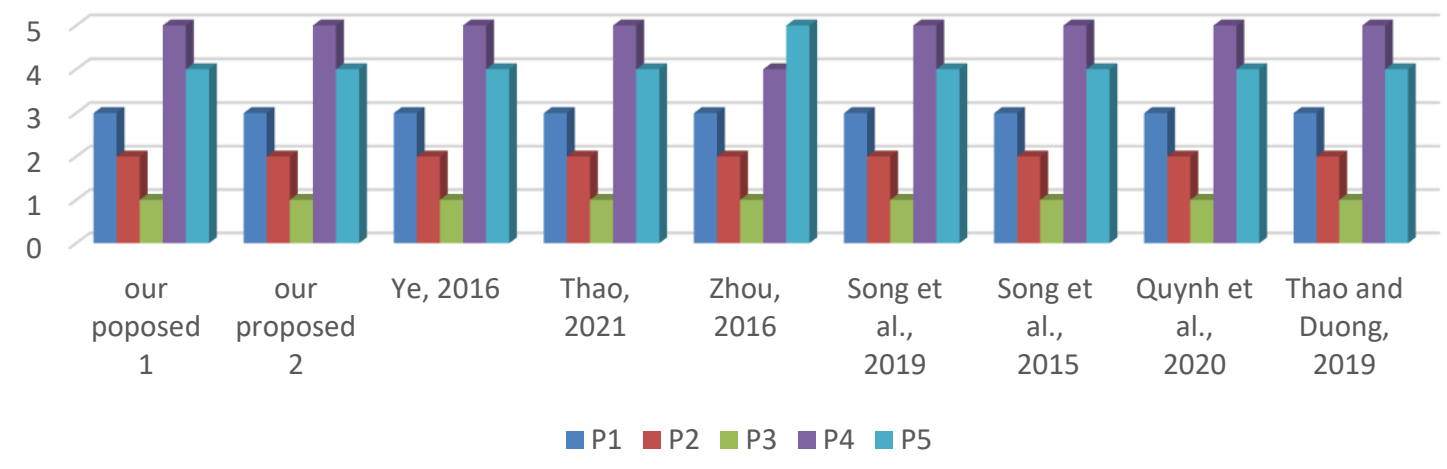

Figure 3. Comparing results of software raking with weight 3 


\section{Conclusion}

The evaluation of software quality based on ISO standards (IOS, 2017) associated with the difficulty is that most of the standards are qualitative. The evaluation considerably depends on the opinion of the decision-maker. When assessing software quality, the evaluation result is affected by the understanding and subjective psychology of decision-makers. Therefore, using the intuitionistic fuzzy set is an appropriate selection for this problem. In this study, we provided some formulas that define similarity measures between different IFSs. Another advantage of this IFSQM model over some other MCDM models is that it combines the entropy induced from the similarity measure to calculate the weights of the criteria. This helps us to avoid emotional mistakes made by decision-makers when assigning weights to criteria. The proposed similarity measures were judged to be superior to existing measures. The evidence for this statement was provided by comparing the proposed measures with other similarity measures. Finally, a software quality model based on the similarity measures of IFSs was introduced. This model is simpler and easier to use for evaluating software quality than some previous models. Moreover, we presented a numerical example to illustrate the proposed model. The proposed method is also limited as it has not mentioned the handling of linguistic variables or the integration of many expert opinions to assess product quality more comprehensively. Those are very meaningful expansion directions and we will continue to study them in the near future.

In the future, we will continue to find other methods to evaluate software quality and will apply similarity, entropy measures to other applied mathematical problems, such as the labeled classification problem (Quynh et al, 2020), clustering problems (Zhou et al., 2016; Thao et al., 2019), decision-making problems (Joshi, 2020; Thao ${ }^{\mathrm{b}}, 2021$ ), applications to supply chain management (Xiao et al., 2020; Thao a , 2021), using IFS and other extended fuzzy sets to "buy online and pick up in store mode" (Wang et al., 2020), and/or other measures as dissimilarity measure (Dinh et al., 2017; Duong and Thao, 2021, Chou et al., 2021); or other methods (Garg and Kumar, 2020; Nguyen et al., 2014; Nguyen and Nguyen, 2015; Zhou et al., 2016; Thao et al., 2019; Thao ${ }^{\mathrm{b}}$, 2021).

Disclosure of potential conflicts of interest: The author declare that they do not have any conflict of interests 
Ethical approval: This article does not contain any studies with human participants or animals performed by any of the authors.

Acknowledgement: This work was supported in part by the Center for Cyberphysical System Innovation from The Featured Areas Research Center Program within the framework of the Higher Education Sprout Project by the Ministry of Education in Taiwan.

\section{References}

Atanassov, K. (1986) Intuitionistic fuzzy sets, Fuzzy sets and Systems, 20(1), 87-96.

Atanassov, K., Gargov, G. (1989). Interval valued intuitionistic fuzzy sets, Fuzzy sets and systems, 31(3), 343-349.

Bharati, S. K., Singh, S. R. (2014). Intuitionistic fuzzy optimization technique in agricultural production planning: A small farm holder perspective, International Journal of Computer Applications 89(6), 17-23.

Burillo P, Bustince H (1996). Entropy on intuitionistic fuzzy sets and on interval-valued fuzzy sets. Fuzzy sets and systems, 78(3), 305-316.

Chang, C.W., Wu, C.R., Lin, H. L(2008) Integrating fuzzy theory and hierarchy concepts to evaluate software quality. Software Quality Journal, 16(2), 263-276.

Chou, S., Duong, T. T., \& Xuan Thao, N. (2021) Renewable energy selection based on a new entropy and dissimilarity measure on an interval-valued neutrosophic set. Journal of Intelligent \& Fuzzy Systems, (Preprint), 1-18.

Dinh, N. V., Thao, N. X., \& Chau, N. M. (2017, September). Distance and dissimilarity measure of picture fuzzy sets. In Conf. FAIR (Vol. 10, p. 2017).

Duong, T.T.T., Thao, N.X(2021), A novel dissimilarity measure on picture fuzzy sets and its application in multi-criteria decision making. Soft Comput, 25(1), 15-25 
Garg, H., Kumar, K. (2020). A novel exponential distance and its based TOPSIS method for interval-valued intuitionistic fuzzy sets using connection number of SPA theory. Artificial Intelligence Review, 53(1), 595-624.

Hung, W. L., \& Yang, M. S. (2006). Fuzzy entropy on intuitionistic fuzzy sets. International Journal of Intelligent Systems, 21(4), 443-451.

Hwang, C.M., Yang, M.S., Hung, W.L., Lee, M.G. (2012) A similarity measure of intuitionistic fuzzy sets based on the Sugeno integral with its application to pattern recognition. Information Sciences, 189, 93-109.

International Organization for Standardization (IOS), 2017. https://www.iso.org/standard/35733.html

Joshi, R. (2020). A new multi-criteria decision-making method based on intuitionistic fuzzy information and its application to fault detection in a machine. Journal of Ambient Intelligence and Humanized Computing, 11(2), 739-753.

Li, D., Cheng, C. (2002) New similarity measures of intuitionistic fuzzy sets and application to pattern recognition. Pattern Recognition Lett. 23 (1-3), 221-225.

Li, J., Zeng, W. (2015), A new dissimilarity measure between intuitionistic fuzzy sets and its application in multiple attribute decision making, Journal of Intelligent \& Fuzzy Systems 29(4), 1311-1320.

Li, Q., Zhao, X., Wei, G. (2014) Model for software quality evaluation with hesitant fuzzy uncertain linguistic information. Journal of Intelligent \& Fuzzy Systems, 26(6), 2639-2647.

Liang, Z., Shi, P. (2003) Similarity measures on intuitionistic fuzzy sets. Pattern Recognition Letters, 24(15), 2687-2693.

Liu, B., Shen, Y., Mu, L., Chen, X., Chen, L. (2016) A new correlation measure of the intuitionistic fuzzy sets, Journal of Intelligent \& Fuzzy Systems 30(2), 1019-1028. 
Nguyen, X. T., Nguyen, VD., \& Nguyen, D. D. (2014). Rough fuzzy relation on two universal sets. International Journal of Intelligent Systems and Applications, 6(4), 49-55.

Nguyen, XT., Nguyen, VD (2015) "Support-Intuitionistic Fuzzy Set: A New Concept for Soft Computing", International Journal of Intelligent Systems and Applications (IJISA), vol.7, no.4, pp.11-16.

Papakostas, G. A., Hatzimichailidis, A. G., Kaburlasos, V. G. (2013) Distance and similarity measures between intuitionistic fuzzy sets: A comparative analysis from a pattern recognition point of view. Pattern Recognition Letters, 34(14), 1609-1622.

Park, J.H., Hwang, J.H, Park W.J., Wei, H., Lee, S.H(2013) Similarity measure on intuitionistic fuzzy sets. Journal of Central South University, 20(8), 2233-2238.

Rajarajeswari, P., Uma, N. (2013) Intuitionistic fuzzy multi similarity measure based on cotangent function, International Journal of Engineering Research \& Technology 2(11), 1323-1329.

Quynh, T. D., Thao, N. X., Thuan, N. Q., \& Van Dinh, N. (2020, November). A new similarity measure of IFSs and its applications. In 2020 12th International Conference on Knowledge and Systems Engineering (KSE) (pp. 242-246). IEEE.

Shi, L.L., Ye, J. (2013) Study on fault diagnosis of turbine using an improved cosine similarity measure for vague sets, Journal of Applied Sciences 13(10), 1781-1786.

Shidpour, H., Bernard A., Shahrokhi, M. (2013) A Group Decision-making Method based on Intuitionistic Fuzzy Set in the Three-dimensional Concurrent Engineering Environment: A Multi-O bjective Programming Approach, Procedia CIRP 7, 533-538.

Song, Y., Wang, X., Lei, L., Xue, A. (2015). A novel similarity measure on intuitionistic fuzzy sets with its applications. Applied Intelligence, 42(2), 252-261. 
Song, Y., Wang, X., Quan, W., \& Huang, W. (2019). A new approach to construct similarity measure for intuitionistic fuzzy sets. Soft Computing, 23(6), 1985-1998.

Szmidt E, Kacprzyk J (2001) Entropy for intuitionistic fuzzy sets. Fuzzy sets and systems, 118(3), 467-477.

Szmidt, E., Kacprzyk, J. (2004) A similarity measure for intuitionistic fuzzy sets and its application in supporting medical diagnostic reasoning, Lecture Notes in Artificial Intelligent, 109-121.

Thao, N. X., \& Duong, T. T. T. (2019). Selecting target market by similar measures in interval intuitionistic fuzzy set. Technological and Economic Development of Economy, 25(5), 934-950.

Thao, N.X., Ali M., Smarandache, F. (2019) An intuitionistic fuzzy clustering algorithm based on a new correlation coefficient with application in medical diagnosis, Journal of Intelligent and Fuzzy Systems 36(1), 189-198.

Thao, N. X., Ali, M., Nhung, L. T., Gianey, H. K., \& Smarandache, F. (2019). A new multi-criteria decision making algorithm for medical diagnosis and classification problems using divergence measure of picture fuzzy sets. Journal of Intelligent \& Fuzzy Systems, 37(6), 7785-7796.

Thao $^{\mathrm{a}}$, N. X. (2021). Some new entropies and divergence measures of intuitionistic fuzzy sets based on Archimedean t-conorm and application in supplier selection. Soft Computing, 25(7), 5791-5805.

Thao ${ }^{b}$, N. X. (2021). MOORA models based on new score function of intervalvalued intuitionistic sets and apply to select materials for mushroom cultivation. Neural Computing and Applications, 1-11.

Tian, M.Y(2013) A new fuzzy similarity based on cotangent function for medical diagnosis, Advanced Modeling and Optimization 15(2), 151-156

Vlachos, I. K., \& Sergiadis, G. D. (2007). Intuitionistic fuzzy information-applications to pattern recognition. Pattern Recognition Letters, 28(2), 197206. 
Wang, R., Nan, G., Chen, L., \& Li, M. (2020). Channel integration choices and pricing strategies for competing dual-channel retailers. IEEE Transactions on Engineering Management, 1-15.

$\mathrm{Xu}, \mathrm{Z}$. (2007) Some similarity measures of intuitionistic fuzzy sets and their applications to multiple attribute decision making. Fuzzy Optimization and Decision Making, 6(2), 109-121.

$\mathrm{Xu}, \mathrm{Z}$. (2010) Choquet integrals of weighted intuitionistic fuzzy information, Information Sciences 180(5), 726-736.

Xu, Z.S., Chen, J. (2008) An overview of distance and similarity measures of intuitionistic fuzzy sets. International Journal of Uncertainty, Fuzziness and Knowledge-Based Systems, 16(04), 529-555.

Xuan Thao, N. (2018) A new correlation coefficient of the intuitionistic fuzzy sets and its application, Journal of Intelligent and Fuzzy Systems 35(2):1959-1968.

Xiao, Q., Chen, L., Xie, M., \& Wang, C. (2020). Optimal contract design in sustainable supply chain: Interactive impacts of fairness concern and overconfidence. Journal of the Operational Research Society, 1-20.

Xue, Y., \& Deng, Y. (2020). Entailment for intuitionistic fuzzy sets based on generalized belief structures. International Journal of Intelligent Systems, 35(6), 963-982.

Ye, J. (2010). Two effective measures of intuitionistic fuzzy entropy. Computing, 87(1-2), 55-62.

Ye, J (2011) Cosine similarity measures for intuitionistic fuzzy sets and their applications, Mathematical and Computer Modelling 53, 91-97.

Ye, J. (2016) Similarity measures of intuitionistic fuzzy sets based on cosine function for the decision making of mechanical design schemes. Journal of Intelligent \& Fuzzy Systems 30(1), 151-158.

Zadeh, L.A(1965), Fuzzy sets, Information and control 8(3), 338-353.

Zhang QS, Jiang SY (2008) A note on information entropy measures for vague sets. Inf Sci 178:4184- 4191. 
Zhou, B. (2016) A New Similarity Measure of Intuitionistic Fuzzy Sets Considering Abstention Group Influence and Its Applications. Journal of Intelligent Systems 25(2), 197-208.

Zhou, X., Zhao, R., Yu, F., Tian, H(2016) Intuitionistic fuzzy entropy clustering algorithm for infrared image segmentation, Journal of Intelligent \& Fuzzy Systems 30(3), 1831-1840.

Zhu, Y. J., \& Li, D. F. (2016). A new definition and formula of entropy for intuitionistic fuzzy sets. Journal of Intelligent \& Fuzzy Systems, 30(6), 3057-3066. 
Figures

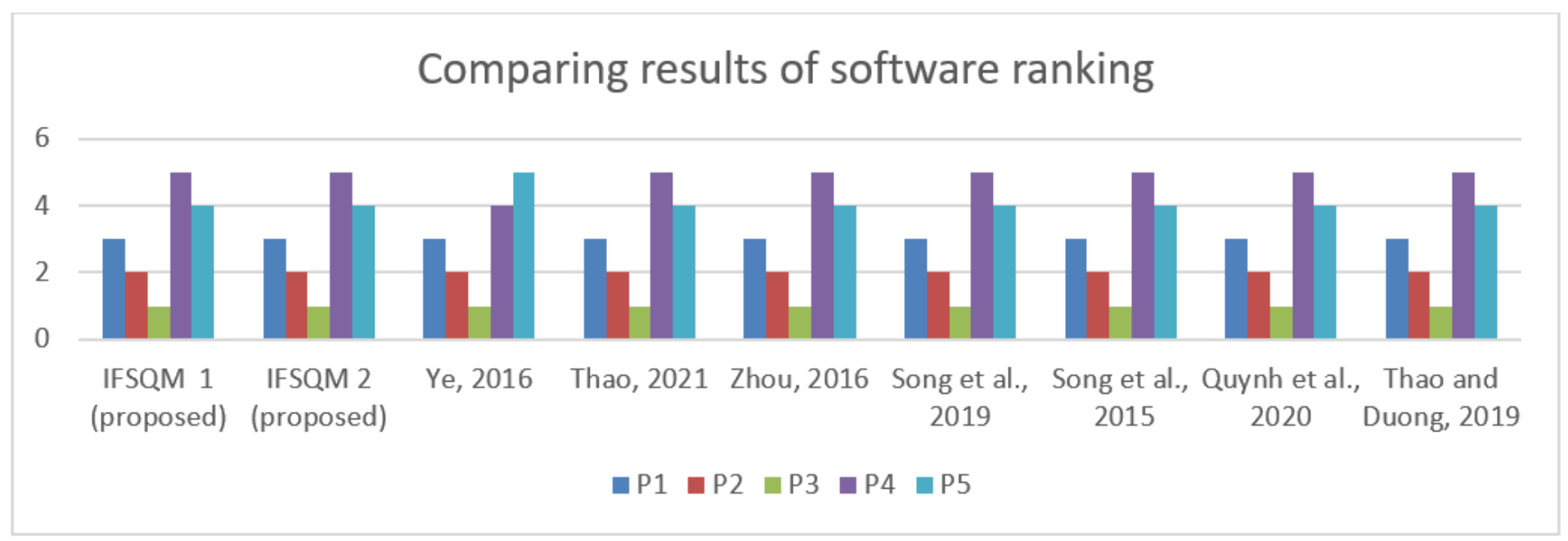

\section{Figure 1}

Comparing results of software raking.

Comparing results of software raking with weight 2

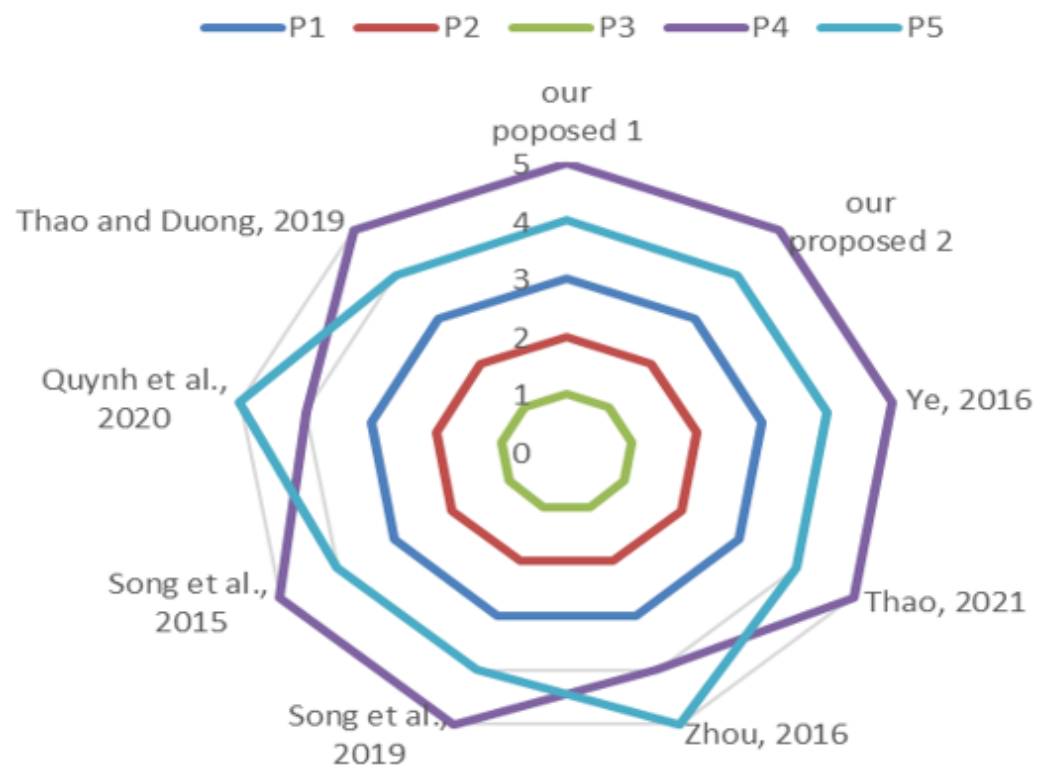

\section{Figure 2}

Comparing results of software raking with weight 2 


\section{Comparing results of software raking with weight 2}

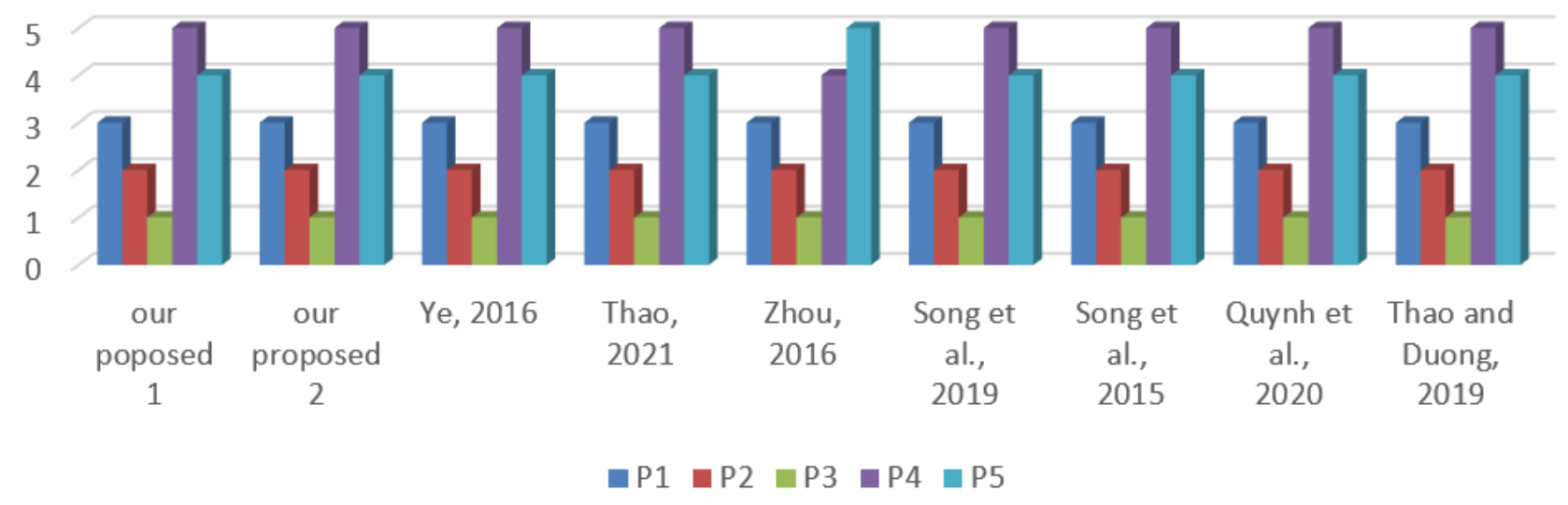

Figure 3

Comparing results of software raking with weight 3 